\title{
Opinion
}

\section{Clinical Virology research and medical education in Greece: An interview with Demetrios A. Spandidos, Professor of Clinical Virology at the University of Crete in Greece}

\author{
IOANNIS N. MAMMAS ${ }^{1-3}$ \\ ${ }^{1}$ Laboratory of Clinical Virology, School of Medicine, University of Crete, 71003 Heraklion; ${ }^{2}$ First Department of Paediatrics, \\ University of Athens School of Medicine, 11527 Athens; ${ }^{3}$ Paediatric Clinic, Aliveri, 34500 Island of Euboea, Greece
}

Received July 22, 2019; Accepted August 26, 2019

DOI: $10.3892 /$ etm.2019.7946

\begin{abstract}
Professor Demetrios A. Spandidos, Professor Emeritus of Clinical Virology at the University of Crete School of Medicine in Crete, Greece, is a pioneer in world research in Virology, Oncology and medical education. He has been the first Professor of Clinical Virology at the University of Crete School of Medicine, the only School of Medicine with a separate Department of Clinical Virology in Greece. According to Professor Spandidos, the understanding of the interactions of viruses with human host cells is what enables the development of new vaccines and new therapies against a wide range of diseases in humans, including cancer. Over the past two decades, the expansion of new knowledge, treatments, prevention and management options and the emerging needs on neonatal and paediatric viral infections have made the role of future paediatric virologists more than necessary. For this reason, he strongly believes that Paediatric Virology should be recognized as a new paediatric subspecialty. Professor Spandidos declares that medical education is a continuous sequence from undergraduate to postgraduate/specialty/subspecialty medical training and continuing learning. He also supports the concept that the future of medical education represents the future of Medicine.
\end{abstract}

\section{Contents}

1. Introduction

2. Questions and Answers

Correspondence to: Dr Ioannis Mammas, Paediatric Clinic, Aliveri, 34500 Island of Euboea, Greece

E-mail: mammasjo@googlemail.com

Key words: Demetrios A. Spandidos, Clinical Virology, Oncology, Paediatric Virology, medical education

\section{Introduction}

Born in Aghios Constantinos, Sparta, Greece, Professor Demetrios A. Spandidos (Fig. 1), Professor Emeritus of Virology at the University of Crete School of Medicine, in Heraklion, Crete, obtained his BSc in Chemistry from the University of Thessaloniki (Greece) in 1971. He completed his PhD in Biochemistry from McGill University in Montreal (Canada) in 1975 entitled 'Genetics and transcription of reovirus' $(1,2)$ and his DSc in Genetics from the University of Glasgow (United Kingdom) in 1989, where he worked as a member of the Senior Scientific Staff at the Beatson Institute for Cancer Research in Glasgow. In 1988, he was elected as Professor of Clinical Virology at the School of Medicine, University of Crete (1989-2015), Director of Clinical Virology, Clinical Bacteriology, Parasitology, Zoonoses and Geographical Medicine Laboratories at the University Hospital of Heraklion, Crete (1989-2015) and Director of the Laboratory of Molecular Oncology and Biotechnology (1988-1998) at the Institute of Biological Research and Biotechnology at the National Hellenic Research Foundation in Athens. He is the founder and editor of nine international scientific journals: International Journal of Molecular Medicine, International Journal of Oncology, Molecular Medicine Reports, Oncology Reports, Experimental and Therapeutic Medicine, Oncology Letters, Biomedical Reports, Molecular and Clinical Oncology, and World Academy of Sciences Journal, while recently he founded the World Academy of Sciences (WAS).

Professor Spandidos is a great pioneer in Virology and Oncology research and his contribution to the recognition and discovery of cancer genes that play pivotal roles in the initiation, differentiation, progression and maintenance of cancer was more than significant (3). He was the first scientist in the field of Oncology to develop and apply the gene transfer technique, which has become a most potent tool to investigate oncogenes (4-7). Thus, his work has resulted in leading investigations worldwide in the field of oncogenes and tumour suppressor genes in a variety of human cancers, and these investigations have resulted in research publications in highly referenced scientific journals (8-15). Professor Spandidos has organized more than 55 international meetings on a variety of areas of Oncology and Molecular Medicine. He has authored 
more than 830 publications and his work has received over 23,000 citations, being the most highly cited scientist in all sciences in Greece for work carried out in Greece. The result of Professor Spandidos efforts has been to establish a scientific tradition in biomedical sciences in Greece and to put Greece on the map of international biomedical research.

Professor Spandidos was the first Professor of Clinical Virology at the University of Crete School of Medicine, the only School of Medicine in Greece with a separate Department of Clinical Virology. The contribution of his laboratory (Fig. 2) to Virology and Oncology research, including HPV Virology in children (16-21), is unique. Professor Spandidos represents the history of Clinical Virology in Greece. To date, he has been a great benefactor of the Paediatric Virology Study Group (PVSG) since its birth (22). He has hosted all 'workshops on Paediatric Virology' organized by PVSG (23-28) and he has co-authored the 2015 proposal of Paediatric Virology subspecialty (29). In 2017, the participation in the '3rd workshop on Paediatric Virology' of two top worldwide experts in Paediatric Virology, Nobelist Laurate Professor of Virology Harald zur Hausen (Germany) and Professor of Neonatology Anne Greenough (UK), was the proof of the high-level scientific standards guaranteed by Professor Spandidos (25) and his fundamental contribution to medical education (30). In the context of the '1st workshop on Paediatric Virology', which was held in Athens on October 10th, 2015, Professor Spandidos received the '2015 George N. Papanicolaou Humanitarian Award' for his outstanding scientific contribution on the wealth, health and future of humanity. This award represents the highest honour awarded by the PVSG.

\section{Questions and Answers}

Question: How fascinating is the world of viruses?

Answer: The world of viruses is extremely fascinating! Viruses represent tiny forms of life with minimal, very simple requirements. Too small to be seen with light microscopes, they had remained invisible and unexplored for too long. There are different types of viruses, which are classified depending on their genetic material. The number of viruses on our planet is excessive and their genetic diversity is really amazing. What is also really fascinating is how these tiny, but powerful, forms of life operate by incorporating their genetic material into the genome of host cells. This interaction between viruses and human host cells is what causes a wide range of diseases in humans, including cancer. The understanding of this interaction is what enables us to develop new vaccines and new therapies against viral infections.

Question: How significant do you believe is for paediatric health professionals to have good knowledge on Virology?

Answer: Paediatric Virology is indeed an increasing educational and research challenge as, over the past two decades, new and old viruses have been demonstrated as causative agents of emerging epidemics; thus, new vaccines, as well as new anti-viral agents are under investigation and are required in paediatric clinical practice. Moreover, the educational paediatric needs are also expanding due to the complexity of the special group of patients, the new technology

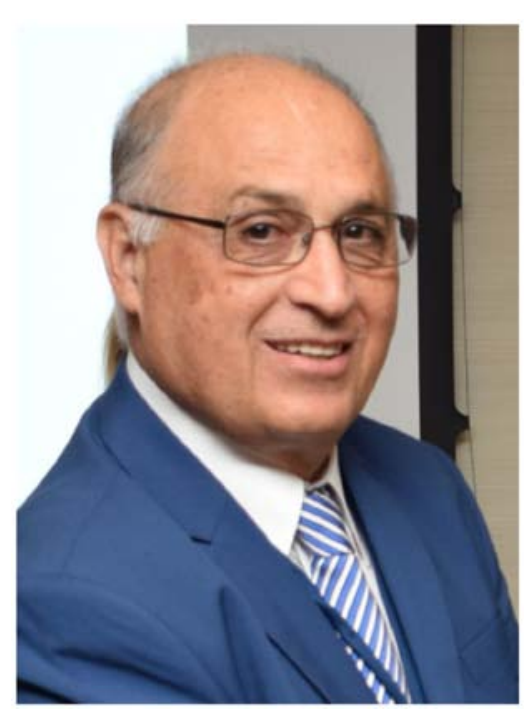

Figure 1. Professor Demetrios A. Spandidos, Professor of Virology at the University of Crete School of Medicine, and Chair of the 23rd World Congress on Advances in Oncology and the 22nd International Symposium on Molecular Medicine, held in Athens, Greece on September, 2018.

methods used in their care and the multidiscipline scientific team workforce required in the management of neonates and children with viral infections. A paediatrician's knowledge of the world of viruses is more than essential and this is a gold educational goal.

Question: In the '1st workshop on Paediatric Virology' in 2015, we proposed Paediatric Virology as a separate paediatric subspecialty. How possible do you consider that this paediatric subspecialty will be officially recognised in the near future? Answer: I strongly believe that Paediatric Virology should be recognized as a new paediatric subspecialty. Its role in the future is mandatory due to this expansion that I described before; expansion of new knowledge, treatments, prevention and management options in parallel to emerging needs on neonatal and paediatric viral infections. I strongly support that this proposal is an educational goal for advanced academic excellence and I declare that this goal should be achieved in the near future.

Question: In 2015, you received the '2015 George N. Papanicolaou Humanitarian Award' by the Paediatric Virology Study Group (PVSG). I would like to have your comment on the contribution of Dr George N. Papanicolaou in Medicine.

Answer: Dr George N. Papanicolaou's pioneering work was really revolutionary. The Pap smear test was the first mass screening test for cancer in the history of Medicine and remains, in fact, as the world's most effective cancer screening test. Today, thousands of women and their descendants owe their lives to this procedure, which was invented by Dr George N. Papanicolaou and became a standard of care in women's health. His patience, his dedication, his hard-working and his high-level ideals were the keys for his success. In one of his letters to his father wrote that: 'My ideal is not to become rich, or to be happy, but to work, to act, to create, to do something worthy of an ethical and strong man'. Unfortunately, the international academic community managed Dr George 


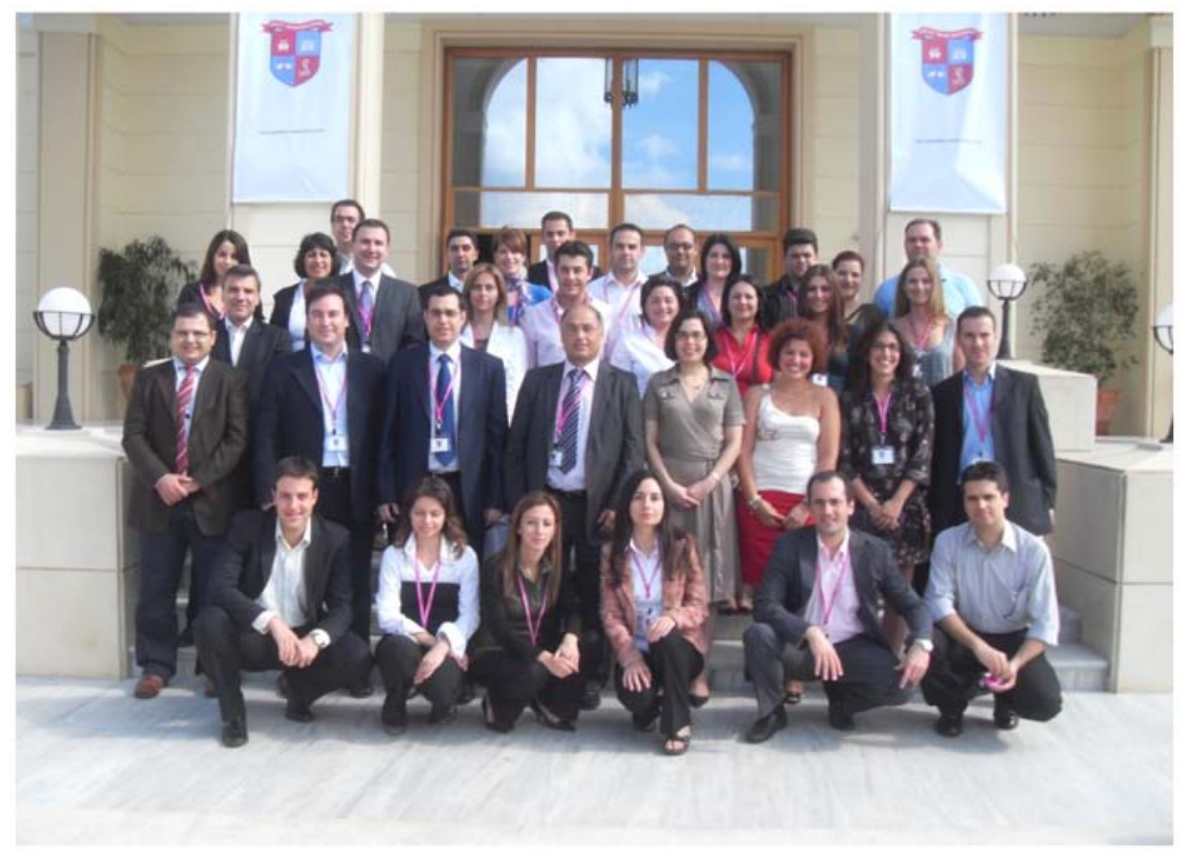

Figure 2. Professor Demetrios A. Spandidos, Professor of Virology at the University of Crete School of Medicine, with his laboratory group and his postgraduate students in Crete, Greece.

N. Papanicolaou with injustice; he definitely should have received the Nobel prize award.

Question: You are considered as one of the most well-known virologists, worldwide. Among your research achievements, which ones do you consider as the most significant?

Answer: My discovery of cellular oncogenes by gene transfer published in Cell and Nature, almost 40 years ago, the transfer of human globin genes to haemopoietic cells and the discovery of avian reovirus. Without any doubt, the identification of cellular oncogenes has probably been the most important discovery in modern cancer research.

Question: The world of viruses is really amazing. And this beauty of the scientific field of Virology is quite modern and is becoming more and more interesting and significant as our interest has moved from the study of the pathophysiology of the viruses to the investigation of therapeutics of viral infections. At what point in your education did you consider a career in Virology?

Answer: The crucial point in my career was when in 1971 I attended with enthusiasm as an undergraduate student the first Laboratory of Virology in Greece at the Theagenion Cancer Institute of Thessaloniki, under the direction of my mentor Joyce Taylor-Papadimitriou. It was then that I was really fascinated by research in Virology and its perspectives in future Medicine.

Question: Your studies and your research experience in top academic and research centres in the US, Canada and the UK were really outstanding. How important was this experience in your career?

Answer: The fact that I had the opportunity to work with top scientists leading research at that time, such as Professor Angus F. Graham at McGill University in Montreal, Canada, and Professors John Paul and Niel M. Wilkie at the Beatson Institute for Cancer Research in Glasgow, was catalytic, indeed. Their mentoring facilitated my research and enhanced my chances for success.

Question: Why did you eventually decide to return to Greece? Answer: To offer my knowledge to my country. This offering is, though, a very significant task. Science in Greece is a really difficult challenge, which is worth it because of this difficulty.

Question: When you decided to return to Greece, research in our country was a really unknown concept. However, with your contribution, you managed to put Greece to the map of worldwide biomedical research. What difficulties did you face and how did you overcome them?

Answer: The most important obstacles were the lack of funding and the lack of modern scientific tradition. For these reasons I tried to create a functional laboratory, which established collaborations with advanced institutes abroad. The organizing of international conferences and the establishment of quality scientific journals helped in this direction.

Question: More than 100 graduate students have obtained their $\mathrm{PhD}$ degree in Greece under your supervision and most of them are pursuing careers abroad in leading institutions in the field of cancer research, as shown by work published in top biomedical journals. However, some have also managed to return to Greece and are currently working at universities and research institutions. What is the future of medical education? Answer: The future of medical education represents the future of Medicine. Training the next generation of doctors is really challenging and our responsibility as their teachers is increased, indeed and we should not underestimate this challenge. Molecular Medicine achievements, rapid developments and uses of new technologies, working in teams, leadership, 
non-clinical roles of the physician, the need for assured quality, cost-effectiveness and accountability, evidence-based and precision Medicine, should be addressed in medical schools more and more and their curricula should be changed. The future demands more of us and more quickly as changes are performed rapidly compared even to the near past. And we should always keep in our mind that medical education is not restricted only to medical schools. Medical education is a continuous sequence from undergraduate to postgraduate, specialty, subspecialty medical training and continuous learning.

Question: What has been your personal force of your achievements in your career?

Answer: The satisfaction of creation. Creation in research. Creation in teaching and giving lectures when invited. Creation in mentoring and encouragement of my students. Creation in publishing. Creation in life.

Question: Which values do you consider the most significant? Answer: Justice. Plato says about justice that 'every knowledge, when separated from justice and the other virtues, ought

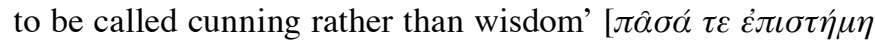

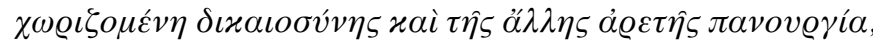

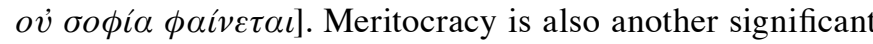
value, which is linked with justice. Posts should be held by selected people according to their talent, their effort and their achievements, rather than factors such as heredity or wealth. When this happens, our mission in our society will have then been achieved. Agesilaus II (444-360 BC), King of ancient Greek Sparta, used to say: 'I shall show that the place does not

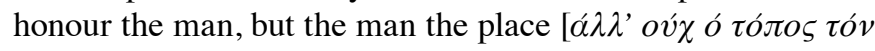

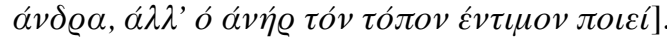

Question: Which is your favourite Greek word?

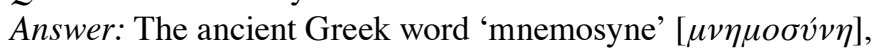
meaning the status to keep our memory. To remember our values and our history. To learn from our values and our history. This was the reason that the Lakedemonian Cultural Centre in Sparta, Greece, was called 'Mnemosyne'. According to ancient Greek mythology, Mnemosyne was the mother of nine Musses.

Question: In our last workshop, you had commented that what is more important than Philosophy is its implementation into real life. What is the secret of your success?

Answer: For any success there are three requirements: Hard work, talent and good luck. If you do not have all three requirements, it is very difficult to succeed. What is also essential is to recognize your faults and learn from them. Not all experiments are successful. But you do learn more from the experiments that do not succeed, compared to the experiments that succeed. Philosophy's implementation into real-life needs hard work, talent and good luck.

Question: In your article entitled 'The cancer story', you finish your article with the poem of the Alexandrian poet C.P. Cavafy entitled 'Ithaka' (4). What is 'Ithaka' for you?

Answer: To continue to work as long as my mind is functional. To admire the academic achievements of my students. To have their appreciation and their recognition. To inspire the young generation of my country, Greece.

Question: What advice would you give to a young scientist, who wishes to start a career in Virology?

Answer: To select a good mentor and to work hard. And as we mentioned before, if there is talent and good luck, then the road to success will be open.

Question: What advice would you give to a young paediatrician?

Answer: Clinical practice of excellence in parallel to research and new knowledge and continuous learning. This balance is what is necessary for all children's health providers, who support what is the most valuable in life, the life of our children.

Question: Thank you for your mentoring, your support and your advice all these years. Your paradigm of academic excellence, dedication and hard-work is what inspire all the members of the PVSG.

\section{Acknowledgements}

This article is published in the third supplement issue of the Experimental and Therapeutic Medicine, which is dedicated to Paediatric Virology. This edition is performed in the context of the '5th workshop on Paediatric Virology' (Sparta, Greece, October 12, 2019) organized by the Paediatric Virology Study Group (PVSG) and supported by the Department of Clinical Virology of the University of Crete School of Medicine and the First Department of Paediatrics of the University of Athens School of Medicine. I would like to thank Professor Demetrios A. Spandidos for this educational and inspirational interview-style article. I would also like to thank all the members of the PVSG for their interesting questions to Professor Spandidos and their valuable comments.

\section{References}

1. Spandidos DA: Genetics and transcription of reovirus (PhD Thesis). McGill University, Montreal, 1975.

2. Spandidos DA and Graham AF: Physical and chemical characterization of an avian reovirus. J Virol 19: 968-976, 1976.

3. Bonavida B: In Honor of Professor Demetrios A. Spandidos. Critical Reviews ${ }^{\mathrm{TM}}$ in Oncogenesis 22: v-v, 2017.

4. Spandidos DA: The cancer story. Cancer Biol Ther 3: 1184-1186, 2004.

5. Spandidos DA and Siminovitch L: Transfer of anchorage independence by isolated metaphase chromosomes in hamster cells. Cell 12: 675-682, 1977.

6. Spandios DA and Siminovitch L: Transfer of the marker for morphologically transformed phenotype by isolated metaphase chromosomes in hamster cells. Nature 271: 259-261, 1978.

7. Spandidos DA and Wilkie NM: Malignant transformation of early passage rodent cells by a single mutated human oncogene. Nature 310: 469-475, 1984.

8. Spandidos A and Wilkie NM: The normal human H-ras1 gene can act as an onco-suppressor. Br J Cancer Suppl 9: 67-71, 1988.

9. Spandidos DA, Frame M and Wilkie NM: Expression of the normal H-rasl gene can suppress the transformed and tumorigenic phenotypes induced by mutant ras genes. Anticancer Res 10: 1543-1554, 1990.

10. Spandidos DA and Kerr IB: Elevated expression of the human ras oncogene family in premalignant and malignant tumours of the colorectum. Br J Cancer 49: 681-688, 1984. 
11. Wyllie AH, Rose KA, Morris RG, Steel CM, Foster E and Spandidos DA: Rodent fibroblast tumours expressing human myc and ras genes: Growth, metastasis and endogenous oncogene expression. Br J Cancer 56: 251-259, 1987.

12. Field JK, Spandidos DA, Stell PM, Vaughan ED, Evan GI and Moore JP: Elevated expression of the c-myc oncoprotein correlates with poor prognosis in head and neck squamous cell carcinoma. Oncogene 4: 1463-1468, 1989.

13. Field JK, Spandidos DA, Malliri A, Gosney JR, Yiagnisis M and Stell PM: Elevated P53 expression correlates with a history of heavy smoking in squamous cell carcinoma of the head and neck. Br J Cancer 64: 573-577, 1991.

14. Field JK, Pavelic ZP, Spandidos DA, Stambrook PJ, Jones AS and Gluckman JL: The role of the p53 tumor suppressor gene in squamous cell carcinoma of the head and neck. Arch Otolaryngol Head Neck Surg 119: 1118-1122, 1993.

15. Spandidos DA, Lamothe A and Field JK: Multiple transcriptional activation of cellular oncogenes in human head and neck solid tumours. Anticancer Res 5: 221-224, 1985.

16. Mammas IN: Human papillomavirus HPV in adults and children (PhD Thesis). University of Crete School of Medicine, Heraklion, 2006.

17. Mammas IN, Sourvinos G, Michael C and Spandidos DA: Human papilloma virus in hyperplastic tonsillar and adenoid tissues in children. Pediatr Infect Dis J 25: 1158-1162, 2006.

18. Mammas I, Sourvinos G, Michael C and Spandidos DA High-risk human papilloma viruses (HPVs) were not detected in the benign skin lesions of a small number of children. Acta Paediatr 97: 1669-1671, 2008.

19. Mammas IN, Sourvinos G and Spandidos DA: Human papilloma virus (HPV) infection in children and adolescents. Eur J Pediatr 168: 267-273, 2009.

20. Mammas IN, Sourvinos G, Vakonaki E, Giamarelou P, Michael C and Spandidos DA: Novel human papilloma virus (HPV) genotypes in children with recurrent respiratory papillomatosis. Eur J Pediatr 169: 1017-1021, 2010.

21. Mammas IN, Sourvinos G and Spandidos DA: The paediatric story of human papillomavirus (Review). Oncol Lett 8: 502-506, 2014.

22. Mammas IN, Theodoridou $M$ and Spandidos DA: The development of the Paediatric Virology Study Group: Ten years in the making. Exp Ther Med 13: 363, 2017.
23. Mammas IN, Greenough A, Theodoridou M, Kramvis A, Christaki I, Koutsaftiki C, Koutsaki M, Portaliou DM, Kostagianni G, Panagopoulou P, et al: Current views and advances on Paediatric Virology: An update for paediatric trainees. Exp Ther Med 11: 6-14, 2016.

24. Mammas IN, Theodoridou M, Kramvis A, Thiagarajan P, Gardner S, Papaioannou G, Melidou A, Koutsaki M, Kostagianni G, Achtsidis V, et al: Paediatric Virology: A rapidly increasing educational challenge. Exp Ther Med 13: 364-377, 2017.

25. Mammas IN and Spandidos DA: Athens-based meeting to discuss the paediatric virology crossroad in October 2017. Acta Paediatr 106: 1536, 2017.

26. Mammas IN, Greenough A, Theodoridou M, Kramvis A, Rusan M, Melidou A, Korovessi P, Papaioannou G, Papatheodoropoulou A, Koutsaftiki C, et al: Paediatric Virology and its interaction between basic science and clinical practice (Review). Int J Mol Med 41: 1165-1176, 2018.

27. Mammas IN, Theodoridou M, Thiagarajan P, Melidou A, Papaioannou G, Korovessi P, Koutsaftiki C, Papatheodoropoulou A, Calachanis M, Dalianis T, et al: A paediatric influenza update 100 years after the Skyros island Spanish flu outbreak. Exp Ther Med 17: 4327-4336, 2019.

28. Mammas IN, Dalianis T, Doukas SG, Zaravinos A, Achtsidis V, Thiagarajan P, Theodoridou M and Spandidos DA: Paediatric virology and human papillomaviruses: An update. Exp Ther Med 17: 4337-4343, 2019.

29. Mammas IN, Greenough A, Theodoridou M and Spandidos DA: Paediatric Virology: A new paediatric subspecialty? A proposal at the Workshop on Paediatric Virology, Athens, October 10 , 2015. Exp Ther Med 11: 3-5, 2016.

30. Mammas IN and Spandidos DA: The subspecialty of Paediatric Virology: A 'mosaic tile' in future Paediatrics. Exp Ther Med 12: 539-540, 2016.

This work is licensed under a Creative Commons Attribution-NonCommercial-NoDerivatives 4.0 International (CC BY-NC-ND 4.0) License. 